\title{
NEW BOUNDARY VALUE PROBLEMS FOR HIGHER ORDER IMPULSIVE FRACTIONAL DIFFERENTIAL EQUATIONS AND THEIR SOLVABILITY
}

\author{
YUJi LiU AND XiAOHUI YANG
}

\begin{abstract}
Firstly, the surveys for studies on boundary value problems for higher order ordinary differential equations and for higher order fractional differential equations are given. Secondly a simple review for studies on solvability of boundary value problems for impulsive fractional differential equations is presented. Thirdly we propose four classes of higher order linear fractional differential equations and give their exact piecewise continuous solutions. Fourthly we propose some new classes of boundary value problems for higher order fractional differential equations with impulse effects. Fifthly we establish new general methods for converting boundary value problems of impulsive fractional differential equations with the Riemann-Liouville fractional derivatives or Caputo fractional derivatives to equivalent integral equations. Sixthly by employing fixed point theorems in Banach space, we establish new existence results of solutions for these boundary value problems. Seventh, some remarks are given to show that many methods in known papers are un-suitable. Eighth, some examples are presented to illustrate the efficiency of the results obtained. Finally, possible trends of researches are given at the end of the paper.
\end{abstract}

Mathematics subject classification (2010): 26A33, 34A08, 34A34, 34A12, 45J08, 34A37, 34K15, 34B40.

Keywords and phrases: Riemann-Liouville fractional derivative, Caputo fractional derivative, higher order fractional differential equation, impulse effect, boundary value problem, the continuation theorem in coincidence degree theory, the Schauder's fixed point theorem.

\section{REFERENCES}

[1] R. P. Agarwal, Boundary Value Problems for Higher Order Differential Equations, World Scientific, Singapore, 1986

[2] B. Ahmad, A. Alsaedi, A. Assolami, Relationship between lower and higher order anti-periodic boundary value problems and existence results, Journal of Computational Analysis and Applications 16 (2) (2014) 210-219.

[3] R. P. Agarwal, M. Benchohra And S. Hamani, A survey on existence results for boundary value problems of nonlinear fractional differential equations and inclusions, Acta Appl. Math. 109 (2010) 973-1033.

[4] R. P. Agarwal, M. Benchohra And B. A. Slimani, Existence results for differential equations with fractional order and impulses, Mem. Differential Equations Math. Phys. 44 (2008) 1-21.

[5] R. P. Agarwal, M. Bohner, P. J. Y. Wong, Positive solutions and eigenvalues of conjugate boundary value problems, Proceedings of the Edinburgh Mathematical Society (Series 2), 42 (2) (1999) 349-374.

[6] R. P. Agarwal, D. O'Regan, Positive solutions for $(p, n-p)$ conjugate boundary value problems, Journal of Differential Equations 150 (2) (1998) 462-473.

[7] B. AhmAD, J. J. NiETo, Existence of solutions for nonlocal boundary value problems of higher-order nonlinear fractional differential equations, Abstract and Applied Analysis, 2009, article ID494720, 9 pages.

[8] B. Ahmad And S. Sivasundaram, Existence of solutions for impulsive integral boundary value problems involving fractinal differential equations, Nonlinear Anal. Hybrid Syst. 3 (2009) 251-258. 
[9] B. Ahmad And S. Sivasundaram, Existence of solutions for impulsive integral boundary value problems of fractional order, Nonlinear Anal. Hybrid Syst. 4 (2010) 134-141.

[10] B. Ahmad, S. Sivasundaram, Existence results for nonlinear impulsive hybrid boundary value problems involving fractional differential equations, Nonlinear Analysis: Hybrid Systems 3 (2009) 251-258.

[11] B. AHMAD, S. SivASUNDARAM, Existence of solutions for impulsive integral boundary value problems of fractional order, Nonlinear Anal. Hybrid Syst. 4 (2010) 134-141.

[12] C. BAI, Impulsive periodic boundary value problems for fractional differential equation involving Riemann-Liouville sequential fractional derivative, J. Math. Anal. Appl. 384 (2) (2011) 211-231.

[13] C. BAI, Solvability of multi-point boundary value problem of nonlinear impulsive fractional differential equation at resonance, Electron. J. Qual. Theory Differ. Equ. 89 (2011) 1-19.

[14] C. BAI, Existence result for boundary value problem of nonlinear impulsive fractional differential equation at resonance, Journal of Applied Mathematics and Computing 39 (1-2) (2012) 421-443.

[15] J. H. BARRETT, Differential equations of non-integer order, Canad. Journal Math. 6 (4) (1954) 529541.

[16] M. BelmeKki, J. J. Nieto, R. RodrigueZ-Lopez, Existence of solution to a periodic boundary value problem for a nonlinear impulsive fractional differential equation, Electron. J. Qual. Theory Differ. Equ. 16 (2014) 1-27.

[17] G. BonAnno, R. Rodriguez-López, S. TERsian, Existence of solutions to boundary value problem for impulsive fractional differential equations, Fractional Calculus and Applied Analysis 17 (3) (2014) 717-744.

[18] D. D. Bainov, P. S. Simeonov, Systems with Impulse Effect: Stability, Theory and Applications, Wiley, New York, 1989.

[19] M. Benchohra, B. A. Slimani, Existence and uniqueness of solutions to impulsive fractional differential equations, Electron. J. Diff. Equ. 10 (2009) 1-11.

[20] C. J. Chyan, J. Henderson, Positive solutions of $2 m$ th-order boundary value problems, Applied Mathematics Letters 15 (6) (2002) 767-774.

[21] R. Caponetto, G. Dongola, L. Fortuna, I. Petrás̀, Fractional order systems: Modeling and control applications, World scientific series on nonlinear science, Series A, vol. 27, World Scientific Publishing Co. Pte. Ltd. Singapore, 2010.

[22] J. M. DaVis, P. W. EloE, J. Henderson, Triple positive solutions and dependence on higher order derivatives, J. Math. Anal. Appl. 237 (2) (1999) 710-720.

[23] J. M. DAVIS, J. HENDERSON, P. J. Y. Wong, General Lidstone problems: multiplicity and symmetry of solutions, Journal of Mathematical Analysis and Applications 251 (2) (2000) 527-548.

[24] J. M. DAVIS, J. HENDERSON, Triple positive solutions for $(k, n-k)$ conjugate boundary value problems, Mathematica Slovaca, 51 (3) (2001) 313-320.

[25] J. M. DAVis, J. Henderson, P. K. RAJENDRA, Eigenvalue intervals for nonlinear right focal problems, Applicable Analysis 74 (1-2) (2000) 215-231.

[26] P. W. Eloe, J. Henderson, Singular nonlinear $(k, n-k)$ conjugate boundary value problems, Journal of Differential Equations 133 (1) (1997) 136-151.

[27] P. W. Eloe, J. Henderson, Singular nonlinear $(n-1,1)$ conjugate boundary value problems, Georgian Mathematical Journal 4 (5) (1997) 401-412.

[28] P. W. Eloe, J. Henderson, Positive solutions for $(n-1,1)$ conjugate boundary value problems, Nonlinear Analysis: TMA, 28 (10) (1997) 1669-1680.

[29] K. M. FURATI AND N. TATAR, An existence result for a nonlocal fractional differential problem, J. Fract. Calc. 26 (2004) 43-51.

[30] G. FELtrin, F. ZAnolin, Existence of positive solutions in the superlinear case via coincidence degree: the Neumann and the periodic boundary value problems, arXiv preprint arXiv:1503.04954, 2015.

[31] M. FENG, X. ZHANG, W. GE, et al., New existence results for higher-order nonlinear fractional differential equation with integral boundary conditions, Boundary Value Problems, (2011) 2011, Article ID 720702, 20 pages.

[32] M. FEckAn, Y. ZHOU, J. WANG, On the concept and existence of solution for impulsive fractional differential equations, Commun. Nonlinear Sci. Numer. Simulat. 17 (2012) 3050-3060.

[33] T. GUO, W. JiAng, Impulsive problems for fractional differential equations with boundary value conditions, Comput. Math. Appl. 64 (2012) 3281-3291. 
[34] R. Hilfer, Applications of Fractional Calculus in Physics, World Scientific, River Edge, NJ, 2000.

[35] J. Henderson AND A. OUAhab, Impulsive differential inclusions with fractional order, Comput. Math. Appl. 59 (2010) 1191-1226.

[36] J. Henderson, A. OuAhab, Impusive differential inclusions with fractioanl order, Comput. Math. Appl. 59 (2010) 1191-1226.

[37] J. HeNDERSON, W. YIN, Singular $(k, n-k)$ boundary value problems between conjugate and right focal, Journal of Computational and Applied Mathematics 88 (1) (1998) 57-69.

[38] V. A. IL'IN, E. I. MoISEEV, An a priori bound for a solution of the problem conjugate to a nonlocal boundary value problem of the first kind, Differ. Equations 24 (5) (1988) 795-804.

[39] D. JiANG, H. LIU, Existence of positive solutions to $(k, n-k)$ conjugate boundary value problems, Kyushu Journal of Mathematics 53 (1) (1999) 115-125.

[40] N. Kosmatov, On a singular conjugate boundary value problem with infinitely many solutions, Math. Sci. Res. Hot-Line 4 (2000) 9-17.

[41] L. Kong, T. LU, Positive solutions of singular $(n, n-k)$ conjugate boundary value problem, Journal of Applied Mathematics and Bioinformatics 5 (1) (2015), 13-24.

[42] A. A. Kilbas, J. J. Trujillo, Differential equations of fractional order: Methods results and problems, I, Applicable Analysis 78 (1) (2010) 159-192.

[43] A. A. Kilbas, J. J. Trujillo, Differential equations of fractional order: methods, results and problems, II, Applicable Analysis 81 (2002) 435-493.

[44] Y. LIU, Global existence of solutions for a system of singular fractional differential equations with impulse effects, J. Appl. Math. and Informatics 33 (3-4) (2015) 327-342.

[45] Y. LIU, Bifurcation techniques for a class of boundary value problems of fractional impulsive differential equations, J. Nonlinear Sci. Appl. 8 (2015) 340-353.

[46] Y. LIU, Existence of solutions of IVPs for differential systems on half line with sequential fractional derivative operators, African Diaspora Journal of Mathematics 18 (1) (2015) 27-54.

[47] Y. LIU, Solvability of Sturm-Liouville boundary value problems for multiple order fractional differential equations, Arab Journal of Mathematical Sciences, 2015, http://dx.doi.org/10.1016/ j.ajmsc.2015.08.001.

[48] Y. LiU, Existence of positive solutions of fractional order elastic beam equation with a non-Carathéodory nonlinearity, Mathematical Methods in the Applied Sciences, 2015. DOI: 10.1002/mma.3560.

[49] V. V. Lakshmikantham, D. D. Bainov and P. S. Simeonov, Theory of Impulsive Differential Equations, World Scientific, Singapore, 1989.

[50] X. LI, F. CHEN, AND X. LI, Generalized anti-periodic boundary value problems of impulsive fractional differential equations, Commun. Nonlinear Sci. Numer. Simulat. 18 (1) (2013) 28-41.

[51] Y. LIU, S. LI, Periodic boundary value problems of singular fractional differential equations with impulse effects, Malaya Journal of Matematik, 3(4) (2015) 423-490.

[52] X. LiU, M. JIA, Existence of solutions for the integral boundary value problems of fractional order impulsive differential equations, Mathematical Methods in the Applied Sciences, 2015, DOI: $10.1002 / \mathrm{mma} 3495$.

[53] X. Lin, D. JiAnG, X. LI, Existence and uniqueness of solutions for singular $(k, n-k)$ conjugate boundary value problems, Comput. Math. Appl. 52 (3) (2006) 375-382.

[54] Z. LiU, X. LI, Existence and uniqueness of solutions for the nonlinear impulsive fractional differential equations, Commun. Nonlinear Sci. Numer. Simulat. 18 (6) (2013) 1362-1373.

[55] P. Li, H. Shang, Impulsive problems for fractional differential equations with nonlocal boundary value conditions, Abstract and Applied Analysis, 2014 (2014), Article ID 510808, 13 pages.

[56] Z. LUO, J. XIE, G. CHEN, Existence of solutions of a second-order impulsive differential equation, Advances in Difference Equations, 2014 (2014): 118.

[57] X. LiU, Y. ZHANG, H. SHI, Existence and nonexistence results for a fourth-order discrete neumann boundary value problem, Studia Scientiarum Mathematicarum Hungarica 51 (2) (2014) 186-200.

[58] V. Lashmikanthan and A. S. Vats ala, Basic theory of fractional differential equations, Nonlinear Anal. 69 (2008) 2715-2682.

[59] Z. LIU, J. WANG, W. WEI, Multipoint BVPs for generalized impulsive fractional differential equations, Appl. Math. Comput. 258 (2015) 608-616.

[60] J. MAWHIN, Topological degree methods in nonlinear boundary value problems, in: CBMS Regional Conference Series in Mathematics 40, American Math. Soc., Providence, R. I., 1979. 
[61] R. MA, Positive solutions for semipositone $(k, n-k)$ conjugate boundary value problems, J. Math. Aanal. Appl. 252 (1) (2000) 220-229.

[62] F. MaInARdi, Fractional Calculus: Some basic problems in continuum and statistical mechanics, in: Fractals and Fractional Calculus in Continuum Mechanics, 291-348, CISM Courses and Lectures 378, Springer, Vienna, 1997.

[63] K. S. Miller ANd B. Ross, An Introduction to the Fractional Calculus and Fractional Differential Equations, John Wiley, New, York, 1993.

[64] I. PodLubnY, Geometric and physical interpretation of fractional integration and fractional differentiation, Fract. Calc. Appl. Anal. 5 (2002) 367-386.

[65] I. Podlubny, Fractional Differential Equations, Mathmatics in Science and Engineering, vol. 198, Academic Press, San Diego, California, USA, 1999.

[66] I. Rachunkova, S. STANEK, A singular boundary value problem for odd-order differential equations, J. Math. Anal. Appl. 291 (2) (2004) 741-756.

[67] K. SHAH, H. KhaliL, R. A. Khan, Investigation of positive solution to a coupled system of impulsive boundary value problems for nonlinear fractional order differential equations, Chaos, Solitons and Fractals 77 (2015) 240-246.

[68] Y. TIAN AND Z. BAI, Existence results for three-point impulsive integral boundary value problems involving fractinal differential equations, Comput. Math. Appl. 59 (2010) 2601-2609.

[69] S. TIAn, W. GAO, Positive solutions of singular $(k, n-k)$ conjugate eigenvalue problem, Journal of Applied Mathematics and Bioinformatics 5 (2) (2015) 85-97.

[70] M. UR REHMAN, P. W. ElOE, Existence and uniqueness of solutions for impulsive fractional differential equations, Appl. Math. Comput. 224 (2013) 422-431.

[71] P. J. Y. Wong, Triple positive solutions of conjugate boundary value problems, Comput. Math. Appl. 36 (9) (1998) 19-35.

[72] X. WANG, Impulsive boundary value problem for nonlinear differential equations of fractional order, Comput. Math. Appl. 62 (2011) 2383-2391.

[73] X. WANG, Existence of solutions for nonlinear impulsive higher order fractional differential equations, Electron. J. Qual. Theory Differ. Equ. 80 (2011) 1-12.

[74] P. J. Y. Wong, R. P. AgarwaL, Singular differential equations with $(n, p)$ boundary conditions, Mathematical and Computer Modelling 28 (1) (1998) 37-44.

[75] G. Wang, B. Ahmad, L. Zhang, J. J. Nieto, Some existence results for impulsive nonlinear fractional differential equations with mixed boundary conditions, Comput. Math. Appl. 62 (2011) $1389-1397$.

[76] G. WANG, B. AhMAD, L. ZHANG, Impulsive anti-periodic boundary value problem for nonlinear differential equations of fractional order, Nonlinear Anal. 74 (2011) 792-804.

[77] G. WANG, B. AhMAD, L. ZHANG, On impulsive boundary value problems of fractional differential equations with irregular boundary conditions, Abstract and Applied Analysis, vol. 2012, Article ID 356132, 18 pages.

[78] X. WANG, C. BAI, Periodic boundary value problems for nonlinear impulsive fractional differential equation, Electron. J. Qual. Theory Differ. Equ. 3 (2011) 1-13.

[79] J. WANG, M. FeCKAn, Y. Zhou, Presentation of solutions of impulsive fractional Langevin equations and existence results, The European Physical Journal Special Topics 222 (8) (2013) 1857-1874.

[80] J. R. WANG, Y. Zhou, M. FeCKAN, Nonlinear impulsive problems for fractional differential equations and Ulam stability, Comput. Math. Appl. 64 (2012) 3389-3405.

[81] C. YUAN, Multiple positive solutions for $(n-1,1)$-type semipositone conjugate boundary value problems of nonlinear fractional differential equations, Electron. J. Qual. Theory Differ. Equ. 2010, 36: $1-12$.

[82] X. YANG, Existence of solutions for $2 n$-order boundary value problem, Appl. Math. comput. 237 (1) (2003) 77-87.

[83] A. YANG, J. Henderson, JR. C. Nelms, Extremal points for a higher-order fractional boundaryvalue problem, Electron. J. Diff. Equ. 161 (2015), 1-12.

[84] W. Yukunthorn, S. K. NTOUyAs, J. TARiboon, Impulsive multiorders Riemann-Liouville fractional differential equations, Discrete Dynamics in Nature and Society 2015 (2015), Article ID 603893,9 pages.

[85] Y. YANG, J. ZHANG, Nontrivial solutions on a kind of fourth-order Neumann boundary value problems, Appl. Math. Comput. 218 (13) (2012) 7100-7108. 
[86] S. ZHANG, Positive solutions to singular boundary value problem for nonlinear fractional differential equation, Comput. Math. Appl. 59 (3) (2010) 1300-1309.

[87] S. ZhANG, Monotone iterative method for initial value problem involving Riemann-Liouville fractional derivatives, Nonlinear Anal. 71 (2009) 2087-2093.

[88] K. ZHAO, Impulsive boundary value problems for two classes of fractional differential equation with two different Caputo fractional derivatives, Mediterranean Journal of Mathematics, 2015, DOI 10.1007/s00009-015-0536-0.

[89] J. ZHOU, M. FENG, Green's function for Sturm-Liouville-type boundary value problems of fractional order impulsive differential equations and its application, Boundary Value Problems 2014, 2014: 69, 21 pages.

[90] K. ZHAO, P. GONG, Positive solutions for impulsive fractional differential equations with generalized periodic boundary value conditions, Adv. Differ. Equ. 225 (2014) 1-15.

[91] W. ZHOU, X. LIU, Existence of solution to a class of boundary value problem for impulsive fractional differential equations, Adv. Differ. Equ. 12 (2014) 1-12.

[92] X. ZHANG, L. LIU, Y. WU, The eigenvalue problem for a singular higher order fractional differential equation involving fractional derivatives, Appl. Math. Comput. 218 (17) (2012) 8526-8536.

[93] W. ZHOU, X. LiU, J. ZHANG, Some new existence and uniqueness results of solutions to semilinear impulsive fractional integro-differential equations, Adv. Differ. Equ. 38 (2015) 1-16.

[94] L. Zhang, N. YAMAZAKI, R. GUO, Positive solutions for impulsive differential equations with mixed monotonicity and optimal control, Abstract and Applied Analysis, 2014 (2014), Article ID 974968, 11 pages.

[95] X. Zhang, C. ZHU, Z. WU, Solvability for a coupled system of fractional differential equations with impulses at resonance, Boundary Value Problems 2013, 2013: 80. 